\title{
Educación popular y educación propia: diálogos desde experiencias educativas en Cauca
}

Popular Education and Self-Education:

Dialogue Between Educational

Experiences in Cauca, Colombia

Educação popular e educação própria:

diálogos a partir de experiências

educacionais no Cauca

Maria Isabel González-Terreros* iD orcid.org/0000-0001-5543-7937

Alfonso Torres-Carrillo** (iD orcid.org/0000-0002-0619--8594

Para citar este artículo: González-Terreros, M. I. y Torres-Carrillo, A. (2020). Educación popular y educación propia: diálogos desde experiencias educativas en Cauca. Revista Colombiana de Educación, l(80), 335-354. https://doi.org/10.17227/rce.num80-11152

\section{(c) $(1) \Theta$}




\section{Resumen}

Este artículo resultado de investigación presenta algunos diálogos entre la educación popular y la educación propia desde discursos y experiencias pedagógicas que han llevado a cabo profesores y dirigentes sociales del departamento del Cauca (Colombia) en instituciones educativas. Las dos corrientes pedagógicas forman parte de las apuestas político-educativas de dos organizaciones que conviven en el Cauca: la Asociación de Instructores y trabajadores de la Educación del Departamento del Cauca (Asoinca) y el Consejo Regional Indígena del Cauca (CRIC). A partir del trabajo de investigación basado en una metodología crítica y participativa, encontramos que, pese a las diferencias entre estas dos corrientes pedagógicas, existe un diálogo profundo de sus sentidos, prácticas y saberes el cual ha posibilitado y fortalecido las construcciones colectivas en algunas experiencias escolares donde convergen. Este artículo, además de presentar los sentidos compartidos: critica al capitalismo, sentido emancipador, contextualismo, fortalecimiento organizativo, transformaciones culturales y subjetivas, y expone algunos criterios convergentes de sus experiencias en cuanto a las orientaciones de sus prácticas educativas.

\section{Palabras clave}

educación popular; educación propia; organizaciones sociales; práctica pedagógica; diálogo de saberes

\section{Keywords}

popular education; intercultural education; social organizations; teaching practice; dialogue of knowledge

\begin{abstract}
This research article presents some dialogues between popular education and self-education from discourses and pedagogical experiences that have been carried out by teachers and social leaders of the department of Cauca, Colombia, in educational institutions. The two pedagogical currents are part of the political and educational projects of two organizations of that department: the Asociación de Instructores y trabajadores de la Educación del Departamento del Cauca (Asoinca) and the Consejo Regional Indigena del Cauca (CRIC). From the research work, based on a critical and participatory pedagogy, we find that, despite the differences between these two pedagogical currents, there is a deep dialogue of their meanings, practices and knowledge which has made possible and strengthened the collective constructions in some school experiences where they converge. This article, in addition to presenting these shared meanings: criticism of capitalism, emancipatory meaning, contextualism, organizational strengthening, cultural and subjective transformations, exposes some convergent of their experiences regarding the orientation of their educational practices.
\end{abstract}

\section{Resumo}

Este artigo, resultado de uma pesquisa, apresenta alguns diálogos entre educação popular e educação própria, a partir de discursos e experiências pedagógicas realizadas por professores e líderes sociais em escolas do departamento do Cauca - Colômbia. As duas correntes pedagógicas fazem parte dos compromissos político-educacionais de duas organizações que coexistem em Cauca: a Associação de Instrutores e Trabalhadores da Educação do Departamento de Cauca (Asoinca) e o Conselho Regional Indígena de Cauca (CRIC). A partir do trabalho de pesquisa baseado em uma metodologia crítica e participativa, constatamos que, apesar das diferenças entre essas duas correntes pedagógicas, há um profundo diálogo de seus significados, práticas e saberes que tem possibilitado e fortalecido as construções coletivas em algumas experiências da escola onde convergem. Além disso, este artigo apresenta alguns sentidos compartidos: crítica ao capitalismo, sentido emancipatório, contextualização, fortalecimento organizacional, transformação cultural e subjetiva, e expõe alguns critérios convergentes de suas experiências quanto às orientações de suas práticas educativas.

\section{Palavras-chave}

educação popular; educação própria; organizações sociais; prática pedagógica, diálogo de conhecimento 


\section{Introducción}

El presente artículo forma parte de los resultados del proyecto de investigación Experiencias pedagógicas para tramitar el conflicto en contextos de guerra. Propuestas desde los sindicatos magisteriales, ${ }^{1}$ en particular de los hallazgos obtenidos con relación a los discursos y las prácticas educativas promovidas desde la Asociación de Institutores y Trabajadores de la Educación del Departamento del Cauca (Asoinca). En dicho departamento también está presente desde hace cinco décadas el Consejo Regional Indígena del Cauca (CRIC), que ha construido sus propuestas pedagógicas basada en la educación propia e intercultural. En la investigación se encontró que en algunas instituciones educativas departamentales confluían ambas concepciones pedagógicas, lo que da lugar a un fructífero diálogo de saberes que enriquece tanto la construcción de propuestas pedagógicas emancipatorias como la discusión entre la educación propia y popular. En este sentido, en el presente artículo realizamos una caracterización de estas dos corrientes pedagógicas y analizamos cómo se expresan en las prácticas educativas de maestros afiliados a Asoinca e integrantes del CRIC y cómo opera dicha confluencia, para finalmente, interpretarla a partir del denominado diálogo de saberes.

Asoinca es un sindicato magisterial que desde hace más de dos décadas le ha dado un giro crítico a su acción gremial y política. El sindicato decidió contribuir a la construcción de poder popular local y regional en los diferentes campos de la vida social (económico, político, cultural y, por supuesto, educativo). En este contexto, desde 1998 logró que el Gobierno departamental permitiera que la propia organización sindical asumiera la capacitación de los maestros. Desde 2004, Asoinca decidió asumir a la educación popular, como una fuente de inspiración pedagógica desde la cual orientar sus acciones formativas e incidir en la práctica pedagógica de sus afiliados.

Esta decisión los llevó a acercarse al grupo de Educación Popular de la Universidad del Cauca y a otros educadores populares del país. Dicho grupo, desde fines de la década de 1990, realizaba unos encuentros regionales e internacionales de educación popular, en los que fue creciendo la participación de los maestros del departamento del Cauca. Desde 2012 (v Encuentro Regional y III Encuentro Internacional) se sumó Asoinca como coorganizador del evento. ${ }^{2}$ El fortalecimiento de dicho vínculo ha sido

1 Financiado por SGP-CIUP UPN (código DSI 454-17). En esta investigación también participaron los profesores Alcira aguilera Morales y Víctor Manuel Rodríguez, de la Universidad Pedagógica Nacional.

2 Conjuntamente, Asoinca y la Universidad del Cauca han realizaron: el Iv Encuentro Internacional y vı regional en el 2013, el v Encuentro Internacional y VII Regional en el 2015 y el vı Encuentro Internacional y VIII Regional en 2017, y el VII Encuentro Internacional y ıx regional. 
decisivo en la conformación de un pensamiento educativo popular por parte del Sindicato, así como de la conformación del Colectivo de Educación Popular del Cauca en 2012. Con el mismo propósito formativo y divulgativo, Asoinca ha respaldado la creación de la Maestría en Educación Popular y la revista Pensamiento Popular, a través de la cual socializa reflexiones pedagógicas y políticas del sindicato, de sus profesores y de educadores populares de América Latina.

Estos antecedentes permiten comprender el posicionamiento que tiene la educación popular en el discurso y la práctica de los maestros afiliados a Asoinca, en particular, de aquellos que integran el Colectivo de Educación Popular del Cauca. ${ }^{3}$ Dicho referente pedagógico ha sido acogido, resignificado y recreado desde las experiencias y reflexiones previas de maestros y colectivos de profesores. Algunos de ellos ya habían iniciado experiencias educativas y proyectos pedagógicos inspirados en otros referentes, como la educación propia ${ }^{4}$ e intercultural, así como en la innovación didáctica en áreas específicas de la educación. De modo tal que las experiencias y reflexiones de sus protagonistas expresan la confluencia de estos discursos pedagógicos.

De esta riqueza educativa y su potencial pedagógico transformador asociado a la educación popular y a la educación propia nos ocuparemos a continuación. En su orden, a partir de una conceptualización de la educación popular y de la educación propia, abordaremos los relatos de algunos maestros sobre sus prácticas educativas; luego, presentamos la confluencia de sentidos y prácticas inspiradas en estas concepciones educativas; por último, realizamos un balance interpretativo desde el diálogo de saberes.

\section{Metodología}

La metodología cualitativa desde un enfoque crítico de tendencia participativa fue la privilegiada en esta investigación porque permite vincular a los actores involucrados en los procesos sociales como sujetos de conocimiento, a la vez que asume la producción de conocimiento como una actividad reflexiva y comprometida. Ello en razón a que esta metodología asume que

3 Conformado por maestros afiliados al sindicato, algunos profesores del Grupo de Educación Popular de la Universidad del Cauca y personas de otras organizaciones sociales del departamento.

4 En el Cauca tienen asiento varias organizaciones indígenas, dos de las más significativas del país: el Consejo Regional Indígena del Cauca, CRIC (mayoritariamente conformada por el pueblo nasa) y Autoridades Indígenas del Suroccidente de Colombia, AIso (pueblo misak). Una de sus principales reivindicaciones ha sido la lucha por la educación propia. En el Pacífico caucano y en la zona del Patía, las comunidades afro también han asumido también la educación propia, conforme a sus tradiciones ancestrales. 
investigadores/actores reflexionan sobre el carácter interpretativo y constructivo de su labor, remplazando el principio de objetividad por el de reflexibilidad, según el cual se dialoga permanentemente sobre los alcances y límites de su posición de observadores, sobre sus propias observaciones y sobre el conocimiento que construyen. (Torres, 2007, p. 101)

Los criterios en general de las investigaciones de corte sociocrítico y participativo están relacionados con el diálogo como una de las estrategias y apuesta epistémica para reconocer a los otros y establecer vínculos directos con las personas de los procesos investigados; la participación e interlocución a lo largo del proceso como espacio colectivo para construir y visibilizar los conocimientos en torno a los objetivos propuestos en el proyecto y el desarrollo del mismo para ir haciendo balance; la socialización de la investigación que posibilita la interlocución de los actores en aras de escuchar sus puntos de vista y discutir acerca de los hallazgos.

En nuestro caso, implicó también reconocer y poner en diálogo las miradas y las voces de los maestros en la reconstrucción de sus prácticas y proyectos pedagógicos, así como aportar a la construcción de la memoria de resistencia que se ha gestado por más de cuatro décadas en las organizaciones magisteriales. En consecuencia, el proyecto se realizó en seis momentos:

1. Acercamientos previos a las organizaciones a través de comunicaciones y encuentros para afinar el proyecto y establecer acuerdos para realizar la investigación.

2. Revisión bibliográfica y documental para tener una contextualización del campo sindical magisterial y de las dos agremiaciones: Asoinca y la Asociación de Institutores de Antioquia (Adida).

3. Ajuste al proyecto: se precisaron algunas preguntas, se planeó el trabajo de campo y se propuso una matriz para recoger la información.

4. Trabajo de campo: visitas a territorio, establecimiento de vínculos con maestros, identificación de experiencias, realización de entrevistas individuales y colectivas y la participación de encuentros de profesores. Los relatos provenientes de estas conversaciones con los educadores de Asoinca constituyen la materia prima de este artículo (véanse las fuentes).

5. Establecimiento de categorías, análisis e interpretación: un primer análisis desde las temáticas iniciales, y un segundo, desde algunas categorías emergentes: identidades organizativas, tensiones, y confluencias entre educación popular y educación propia en el caso del departamento del Cauca, de la que nos ocupamos en este artículo.

6. Balance y socialización de resultados. Se realizó un encuentro de organizaciones sindicales, las que participaron en el estudio y 
otras, de Brasil, México y Argentina. Se redactó un informe final, que dio cuenta de la caracterización e interpretación global de los discursos y prácticas educativas.

\section{Educación popular y educación propia e intercultural}

Antes que todo, es necesario hacer una breve conceptualización de la educación popular y de la educación propia intercultural, para, a partir de estas, reconocer algunos rasgos comunes que nos permiten valorar si una práctica educativa puede considerase como "popular" o "propia/intercultural". Para este cometido, nos apoyamos en una construcción sistemática que hemos venido desarrollando desde tiempo atrás (González, 2005; González, 2011; González, 2015; Torres, 1993; Torres, 2008; Torres, 2016).

Desde una lectura de diferentes prácticas y discursos que se asumen como "educación popular" en América Latina, se encuentra que esta expresión ha tenido diferentes significados, que van desde aquellos que la usan para describir prácticas educativas Ilevadas a cabo por las capas populares de la población, pasando por las que la asumen como la universalización de la instrucción pública, hasta aquellas que la comprenden como "trabajo de liberación a través de la educación" (Brandão, 2006, p. 23) .

Para efectos de este artículo, asumimos este último sentido, dado que es el que ha orientado toda una corriente pedagógica y un movimiento de educadores en América Latina desde la década de 1970, inspirados en las ideas desarrolladas por Paulo Freire en la década anterior. ${ }^{5}$ En efecto, desde ese momento, la educación popular se asumió como un horizonte político y pedagógico emancipador que, a partir de reconocer el carácter político de la educación y posicionarse críticamente frente a la educación dominante, busca fortalecer procesos y movimientos sociales con base en una pedagogía problematizadora, dialógica y participativa.

A partir de estas consideraciones, hemos propuesto la siguiente conceptualización:

por educación popular entendemos un conjunto de prácticas sociales y elaboraciones discursivas, en el ámbito de la educación, cuya intencionalidad es contribuir a que los diversos segmentos de las clases populares se constituyan en sujetos protagonistas de una transformación de la sociedad, en función de sus intereses y de visiones de futuro en un horizonte emancipador. (Torres, 2012, p. 26)

Tomando como base dicha conceptualización, podemos distinguir los siguientes rasgos que la identifican (Torres 1993 y 2008):

5 En particular, sus libros Educación como práctica de la libertad (1968) y Pedagogía del oprimido (1970). 
» Una lectura crítica de la realidad: cuestionamiento radical al carácter capitalista (y colonial) de la sociedad contemporánea y al papel que desempeña la educación institucionalizada en su reproducción.

» Un horizonte político y ético emancipador que inspira y promueve la transformación de los contextos y condiciones que reproducen las diferentes formas de opresión, exclusión y la discriminación.

» Uso de estrategias para potenciar la capacidad de transformación de los sectores dominados desde el fortalecimiento de sus procesos comunitarios, organizativos y de acción colectiva.

» La intención de contribuir a la construcción de sujetos sociales a través de la afectación diferentes dimensiones subjetivas de los actores sociales, tales como la conciencia, el pensamiento, la cultura, la voluntad, la emocionalidad y la corporeidad.

» La creación y utilización de metodologías, didácticas y técnicas contextualizadas, dialógicas, participativas e interactivas.

Dado el carácter escolar de las experiencias educativas referidas, incorporamos un sexto rasgo, que tiene que ver con lo curricular. Dada la preocupación por incidir en la selección de contenidos educativos; en la tradición educativa popular, estos tienden a referirse a problemas significativos del contexto y a desarrollarse en torno a proyectos pertinentes que integran diferentes campos de saber y potencien los procesos organizativos (Torres, 2016).

En el caso de la "educación propia", es el nombre de la propuesta educativa y concepción pedagógica que los pueblos indígenas del Cauca han venido construyendo desde la década de 1970 y que ha sido apropiada por otros pueblos ancestrales de Colombia. Desde la creación del CRIC en 1971, incluyó en su Plataforma Política el mandato programático de "Formar profesores bilingües para educar de acuerdo con la situación de los indígenas y en sus respectivas lenguas".

El concepto de educación intercultural desde la vertiente propia surgió en un encuentro de educación indígena realizado en México en 1982, en el que se discutía acerca de las políticas educativas de plurilingüismo para las comunidades ancestrales con el fin de establecer las lenguas indígenas como oficiales en sus respectivas naciones. En este contexto, se propuso el cambio de nombre de la educación bilingüe bicultural (EBB), como era designada hasta ese momento, por el de educación intercultural bilingüe (EIB), como es nombrada hoy en varios países de la región (Walsh, 2009).

La educación propia en Colombia pertenece a la educación intercultural, ligada a la lucha de los pueblos ancestrales por una educación basada en la autonomía que posibilite educar fortaleciendo la cultura. Se puede afirmar que su perspectiva sobre los proyectos educativos para poblaciones indígenas y afros es convergente con las apuestas de educación intercultural 
que caminan por América Latina, en el sentido de que se reivindican la crítica al modelo homogeneizador, la lengua propia, el papel preponderante de las comunidades en la implementación de las experiencias y la lucha por una sociedad justa. La educación propia plantea la necesidad de otra escuela, una diferente a la impuesta por siglos en sus territorios porque la Iglesia que mantenía internados para los indígenas cumplía un papel adoctrinador y evangelizador que hacía que muchos de ellos se avergonzaran de su identidad cultural.

Para el CRIC, se trata de un proyecto alternativo de educación que se piensa para la supervivencia de los pueblos indígenas y desde allí ha sido construido y desarrollado. Sin embargo, está lejos de ser una propuesta cerrada que no dialoga con otras formas de ver el mundo, como lo afirma una de sus impulsoras:

Cuando hablamos de lo propio en educación no se trata, como algunos creen, de quedarnos exclusivamente en lo local, en aquello interno de las comunidades o en que el conocimiento cultural se encierre sin permitir el intercambio y enriquecimiento con otras culturas. Lo propio tiene que ver con la capacidad de todas y cada una de las comunidades involucradas para orientar, dirigir, organizar y construir los procesos y proyectos educativos desde una posición crítica frente a la educación que se quiere transformar. (Bolaños y Tatay, 2012, 48)

Las primeras escuelas de educación propia se construyeron en 1979 por mandato del $v$ Congreso del CRIC de formar profesores indígenas bilingües. Estas escuelas emergieron de la organización de las comunidades que reflexionaban sobre qué tipo de escuela requerían. En asambleas multitudinarias se decidía sobre las escuelas y el tipo de educación, lo cual contribuyó a delinear en términos pedagógicos, políticos, culturales y epistemológicos lo que es la educación propia en la actualidad.

La educación propia se ha convertido para las comunidades en un proyecto de pervivencia cultural al proponer que a través de la educación se enseñen, no solo los atributos culturales, sino a valorar, vivir y a luchar por su cultura, de manera que se actualice para que sea vivida en el presente con los cambios que vive el mundo, con la pluralidad cultural, con el respeto por conocimientos ancestrales y científicos. Por eso, se trata también de una educación intercultural, como señala Walsh, una interculturalidad crítica que se convierte en un proyecto político de las comunidades. En el caso de la educación propia, podríamos decir que los rasgos que la identifican son:

» Perspectiva crítica de la colonialidad. Dado el carácter emancipatorio de la educación propia, se cuestiona la educación implementada por los Estados ya que ha contribuido a imponer una lógica cultural, social y económica homogeneizante a través de 
la escuela, por ello se aboga por una educación que reconozca y viabilice la pluralidad.

»El fortalecimiento de la identidad cultural desde lo propio. Los atributos, el conocimiento y las prácticas culturales que han sido compartidas y constitutivas de la pervivencia de las comunidades ancestrales son valoradas y entran a formar parte de los proyectos fundamentales de las escuelas.

» La escuela es parte de la apuesta política de comunidades y sus organizaciones. La escuela necesita estar integrada a las comunidades y sus actores para responder a los planes de vida que han construido colectivamente.

»El territorio ancestral es el origen, es el todo. La educación propia aprende y respeta el territorio, pues más allá de ser un lugar, es un espacio de apropiación cultural y simbólico por donde ha transitado la vida de las comunidades y sin el que no habría sido posible su existencia.

» La comunidad. Los vínculos, sus relaciones y prácticas socioculturales fortalecen lo socialmente compartido que es constitutivo de la identidad de las comunidades, por lo tanto, se requiere activar esos aspectos desde las estrategias y contenidos curriculares que se trabajan desde la escuela.

\section{Educación popular y educación propia en las prácticas educativas de Asoinca}

Teniendo en cuenta estos rasgos característicos y acercamiento a la educación popular y propia, encontramos algunas coincidencias entre las dos corrientes. En este apartado presentaremos un acercamiento a las convergencias a partir de los relatos generados en la fase de trabajo de campo realizado a lo largo del periodo 2017-2018. ${ }^{6}$

6 Los testimonios recogidos provienen de algunos dirigentes de Asoinca, de maestros que animan y participan del proyecto de soberanía alimentaria, educadores indígenas nasa, yanakuna y misak, de colectivos de educadores de diferentes instituciones educativas donde se desarrollan prácticas educativas transformadoras, tales como Colegio Agropecuario Totoró, la Institución Educativa Indígena el Mesón, la Institución Educativa Agrícola La Tetilla, la Institución Educativa Agropecuaria Misak (Silvia), la Institución Educativa Santa Rosa (Zona Rural de Popayán) y la Institución Educativa de Balboa. También, de las consultas de textos generados por los dirigentes y afiliados de Asoinca, y de contextos como talleres realizados con el Colectivo de Educadores Populares de Cauca, el periódico El educador caucano, la revista Pensamiento Popular y el trabajo de grado de Miguel Andrés Burbano (2017) en la Maestría de Educación Popular sobre la formación docente desarrollada desde la organización sindical. 


\section{Crítica a la educación capitalista y colonialista}

El contexto discursivo más amplio que orienta las prácticas educativas transformadoras agenciadas por Asoinca y sus maestros afiliados es el que han venido configurando las directivas de la organización desde 1998. A partir de una lectura clasista de la sociedad colombiana, consideran que

el sistema educativo burgués se ha construido bajo paradigmas de dominación, y por su parte, el Estado se ha encargado de legalizar el acto educativo al servicio del capital, no para satisfacer las necesidades del pueblo, sino para usufructo y enriquecimiento de unos pocos. (Asoinca, 2014, p. 9)

A esta crítica al capitalismo se suma la crítica al carácter colonial del sistema y en particular de la educación "que es homogeneizante y no respeta las particularidades ni siquiera geográficas" (R. A. Montaño, entrevista, 2017), o como lo testimonia un profesor:

Los yanakunas en su historia ha sido uno de los territorios que ha tenido más concentración de lo colonial. [...] y la iglesia fue un motor de desarraigo muy significativo porque llegaba con la cruz y la espada y eso generó una ruptura del tejido social. (G. Chávez, 2017)

En las reflexiones que hacen los docentes y dirigentes sobre la educación propia y popular, la crítica al capitalismo y al colonialismo es parte fundamental de la argumentación del porqué es importante una educación alterna, contrahegemónica y emancipatoria que se deslinde de lo que ha sido, y configure otro tipo de propuestas, que no imponga una cultura homogeneizante y una economía mercantil y capitalista.

\section{Sentidos emancipadores de trabajo educativo}

Las prácticas educativas populares y propias son explícitamente intencionales; sus agentes asumen la educación como opción consciente y procuran evidenciarlo a través del discurso y narrativas. En ese sentido, para Asoinca, la educación popular forma parte de los cuatro ejes de acción de su práctica sindical popular: defensa de los derechos laborales y prestacionales; defensa de la educación pública y popular; construcción de la economía popular, y salud. El segundo eje, como lo afirma M. A. Burbano (entrevista, 2017), tiene esa condición de articular todos los cuatro, asumiendo un sentido emancipador de la educación que se proyecta a otras acciones. Una dirigente de la organización sindical en su intervención en un evento pedagógico en Bogotá ratifica el sentido político de la educación popular: tenemos muy claros: El primero de ellos es el concepto de clase, 
consideramos que es a partir de ahí, de generar conciencia que todos pertenecemos a una clase que es la oprimida y podemos generar grandes cambios; hay otro concepto que es el de transformar con los otros y lo logramos con los estudiantes, no podemos movilizarnos solos y esos son los estudiantes y los padres de familia nuestros principales aliados. (M. Córdoba, entrevista, 2017)

Las apuestas emancipatorias están vinculadas aquí con el trabajo conjunto y en búsqueda de la transformación, porque como lo planteó Freire (2006), la educación no es la palanca de la transformación de la sociedad, pero los educadores populares saben su papel en el proceso de cambio. Tal vez por ello, un rasgo recurrente en las intervenciones orales o artículos de los profesores de Asoinca es su referencia a Paulo Freire, sea con citas textuales de sus obras o a planteamientos generales de su pensamiento: "la educación para ir fortaleciendo la parte política y siempre pensando en esa parte esperanzadora de la que habla Paulo Freire" (J. Bermúdez, entrevista, 2017).

También desde la educación propia, el pueblo yanakuna ha venido trabajando en la re-construcción del sentido emancipador de su proyecto educativo, en coherencia con su plan de vida y su cosmovisión ancestral. Uno de sus dirigentes, el profesor Giovanny Sánchez, lo explica:

\begin{abstract}
Hay una sincronía con relación a nuestra apuesta educativa como una apuesta política [...] y esa apuesta política es la construcción de tejido social para generar espacios de vida digna, [...] las apuestas educativas siempre han sido liberadoras, una forma de liberar es la liberación de la madre tierra, pero eso tiene un significado más profundo que es el conocimiento mismo de las culturas, el saber y el conocimiento de esas prácticas de vida; en el contexto Yanakuna el proceso no es ajeno a la liberación del pensamiento. (Entrevista, 2017)
\end{abstract}

La apuesta emancipatoria es una apuesta por educar para la vida, para vivir mejor y hacer un mundo mejor para las generaciones que vendrán, aquí se encuentran las dos tradiciones pedagógicas.

\title{
Articulación de procesos comunitarios y organizativos
}

Un rasgo común de las experiencias educativas relatadas es su articulación a los procesos organizativos y de movilización comunitarios (tanto étnicos o sociales, como gremiales), a los cuales los educadores no son ajenos. Ellos forman parte de organizaciones con las cuales tienen vínculos estrechos en la mayoría de los casos, por eso su labor pedagógica se entiende como orgánica a dichos procesos organizativos y de movilización. Tanto es así, que frente a hechos como los cultivos ilícitos de coca los profesores hicieron trabajo pedagógico con las comunidades. 


\begin{abstract}
Al respecto, comentan que
nosotros hacemos parte de la comunidad y no estamos ajenos a toda esa situación, [...] hicimos muchas asambleas y fuimos a mostrar videos de otros espacios donde las familias se desintegraron, donde todo lo que quedó por el flagelo del narcotráfico, alertando. [...] entonces la comunidad tomó una decisión de que había que erradicar. (J. Bermúdez, entrevista, 2017)
\end{abstract}

Por su parte, Tito Torres, profesor y líder de Asoinca afirma que en su institución educativa "se ha hecho el trabajo más con las comunidades [...] entonces había un proceso minero, desde ahí empezamos a trabajar con el sindicato y empezamos a desarrollar trabajo comunitario con los estudiantes y los docentes" (T. Torres, entrevista, 2017).

Las prácticas educativas insertadas en procesos comunitarios más amplios, referidos a poblaciones étnicas en su conjunto, como los que adelanta el pueblo Yanakuna, tienen un alcance amplio e integral, pues involucran diferentes dimensiones de la vida de las comunidades:

Los compañeros han venido avanzando en las experiencias comunitarias locales, y resulta que hay instituciones que han trascendido a lo comunitario desde la escuela en una sincronía con la comunidad y han podido intervenir en procesos fuertes de gobernabilidad, tienen experiencias pedagógicas en el control territorial, que es el proceso de conservación de las fuentes, de la riqueza natural, conservación y reconocimiento de los sitios sagrados. (Chávez, entrevista, 2017)

Los proyectos educativos pensados desde la educación popular y/o propia, salen de la escuela y se involucran con las familias de los estudiantes y las comunidades en general, favoreciendo la generación de propuestas organizativas que contribuyan a una vida digna en la cual se aporte a la tramitación de los problemas básicos que se viven.

\title{
Cambios culturales y subjetivos
}

Al reivindicar su carácter propiamente educativo la educación popular y propia procura incidir en la trans-formación personal-subjetiva- de los educandos y educadores, y de sus comunidades. La formación de sujetos críticos, autónomos, transformadores y solidarios solo es posible si se afectan los esquemas mentales, subjetivos y culturales. En el caso de los testimonios de los profesores afiliados a Asoinca, quienes más insistieron en ello son los pertenecientes a pueblos indígenas y afro: "Mi función como docente y como Misak, es primero aquí tenemos una visión y una misión y entre ellas está fortalecer la identidad cultural. Desde mi rol trato de fortalecer ese aspecto, la identidad cultural" (F. Tunubalá, entrevista, 2017). 
Entonces están nuestros mayores y que con ellos es que nosotros hacemos un trabajo, digamos, continuo de dinamizar eso, de que reunir a los mayores, reunir a los jóvenes, producir mucho material pedagógico que la gente lo lea, lo conozca. Eso es un trabajo de sensibilización que es fuerte en la nueva generación. Nuestros mayores pues ya viven, la tienen y conservan nuestra cultura, pero la nueva generación es a la que es duro la aculturización en nuestro territorio. (C. P. Sánchez, entrevista, 2018)

La necesidad de reunir a los mayores y a los jóvenes responde a un propósito sociocultural que busca fortalecer en los jóvenes la pertenencia a la comunidad desde atributos culturales que los vinculan con los mayores y con el pasado. La reafirmación del vínculo intergeneracional es una apuesta colectiva que afecta la subjetividad y posibilita hacer partícipe a las comunidades de los procesos educativos de la escuela para que integren los saberes de la comunidad (sobre todo de los abuelos) a la posibilidad de circular y valorar el conocimiento, $y$ hacer del territorio un lugar educativo para los niños y jóvenes que forman parte integral de la comunidad.

\section{Propuestas educativas contextualizadas}

Como se señaló, uno de los rasgos centrales de las prácticas educativas populares es su radical contextualismo. Es decir, siempre tienen a cuestas las realidades del medio local, regional y nacional, a partir de las cuales generan sus iniciativas pedagógicas, y sobre las cuales se busca incidir, transformando aquellas condiciones que impiden el buen vivir comunitario.

En el plano propiamente pedagógico, es fundamental reconocer la importancia que tiene el análisis del contexto en clave política, como condición necesaria para el abordaje de los proyectos y los contenidos educativos:

Hablar de soberanía alimentaria no es un asunto solamente académico, sino también político; nos hace falta la contextualización política tenemos que agotar temas como el escenario del conflicto; necesitamos conocer el contexto político social en el que se mueve en nuestra región y nuestro país. (O. Valencia, entrevista, 2017)

La lectura del contexto resulta central para las acciones educativas. En el caso de los educadores entrevistados, hay múltiples referencias al conflicto armado y otras violencias, a la pobreza y a las actividades ligadas a los cultivos ilícitos.

\section{Diálogo de saberes entre las dos perspectivas}

Para algunos pedagogos populares, el diálogo de saberes ha sido asumido solo como una metodología o propuesta didáctica que busca articular saberes populares y saberes expertos en una práctica educativa. En nuestro 
caso, lo reconocemos como una perspectiva analítica que posibilita reconocer e interpretar el intercambio de sentidos, criterios, modos de hacer y relacionarse entre dos o más movimientos sociales o procesos educativos; dicho sentido, es equivalente a los conceptos de ecología de saberes y de traducción propuestos por Santos (2000), para referirse a la necesidad de ampliar los marcos de referencia para interpretar la realidad social más allá del conocimiento académico, y valorando los conocimientos gestados desde los propios movimientos sociales.

En la tradición de la educación popular, el diálogo, en particular el diálogo de saberes, no es solo un recurso didáctico para usar en algún momento. En Freire (1970), el diálogo es una matriz pedagógica fundamentada en una concepción antropológica: los seres humanos somos inacabados, necesitamos de los otros para "ser más"; por ello, el diálogo es una interacción comunicativa horizontal basada en la humildad, el amor, la fe y la esperanza. También es, para Freire (1970), una acción cultural, que permite la formación de los sujetos a nivel individual y comunitario.

El concepto de diálogo de saberes se posiciona como un referente de la educación popular y de la investigación participativa en la década de 1980, de la mano de la valoración de las culturas populares y de los saberes de la gente común. Uno de los autores que más ha contribuido a su conceptualización es el pedagogo argentino Alfredo Guiso, para quien el diálogo de saberes "es una clave epistémica y pedagógica para formar sujetos constructores y defensores eficaces de la cultura, capaces de promover un desarrollo que los dignifique y los reconcilie con la naturaleza" (2015, p. 31).

En contextos educativos, este principio pedagógico genera conocimientos solidarios y ecologías culturales que propician la comunicación intercultural y la democratización. Así, el diálogo de saberes permite una dinámica en la que saberes y conocimientos tienen que ser recuperados, deconstruidos, resignificados y recreados, dado que estos se enmarcan en matrices culturales más amplias, tal como lo expresa Guiso (2015), "las prácticas educativas populares tienen ecologías abiertas, pluridimensionales, conjuntivas, solidarias y propiciadoras de cambios en la comprensión, en la emoción, en la expresión y en la acción" (p. 29).

Esta perspectiva, en la que el diálogo de saberes desborda los límites de lo didáctico, para ser visto como un asunto epistémico, pedagógico y político, es pertinente en esta investigación, dado que en las prácticas educativas confluyen horizontes políticos y sentidos emancipadores provenientes de dos procesos organizativos de amplia trayectoria. Dicho diálogo lo evidenciamos en cada una de las dos perspectivas educativas reconocidas en las prácticas analizadas, así como en los procesos de articulación como movimientos, en aquellas prácticas escolares donde confluyen, como en el proyecto de soberanía alimentaria, presente en varias instituciones educativas, y en sus reflexiones pedagógicas. 
Aquí es importante mencionar que, en algunos momentos, las dos organizaciones tuvieron diferencias generadas por la aplicación de algunas políticas educativas a comienzos del nuevo siglo. Es el caso del Decreto 0591 del 2009 de la Secretaría de Educación Departamental del Cauca, que estableció las instituciones educativas oficiales que atienden población ancestral para que fueran dirigidas por las autoridades indígenas. La expedición de este decreto generó tensiones por el hecho de que el CRIC en estas instituciones educativas desarrolla su propuesta educativa propia, y allí laboraban algunos profesores afiliados a Asoinca que no estuvieron de acuerdo. Otro motivo de tensión fue que Asoinca no compartía la forma de contratación de maestros que del CRIC y solicitó concursos públicos para suplir las vacantes.

Pese a las tensiones —y tal vez por ellas—, después de más de una década, lo que se ha encontrado es un acercamiento entre las dos organizaciones para avanzar en las apuestas políticas y educativas que comparten. Ello lo pudimos constatar en la investigación, por lo menos en tres niveles: su confluencia en las dinámicas de movilización colectiva adelantadas en el departamento del Cauca, en sus encuentros en torno al desarrollo de varios proyectos culturales y educativos, y en las confluencias discursivas que dan cuenta de los sentidos pedagógicos de tales prácticas.

Los procesos de defensa del territorio, de la educación pública y de la vida han sido espacios fundamentales para el encuentro y diálogo crítico entre las dos organizaciones. Dirigentes y profesores de ambas describen algunos momentos en que, en medio de marchas, talleres, reuniones, tomas de territorio o caminatas, se han encontrado, debatido, aprendido. Pero, sobre todo, en el último tiempo han compartido las propuestas y las acciones de resistencia en el departamento liderando e involucrando a otras organizaciones y comunidades. Este diálogo en el escenario político lo sintetiza la siguiente reflexión de un maestro y dirigente de Asoinca:

Con el CRIC no tenemos inconveniente porque nos encontramos, y ¿dónde nos encontramos? en el punto de encuentro en la movilización y la huelga, ahí nos encontramos todos, para eso son esos trabajos, [...] nos encontramos en la recuperación de suelos, de la tierra, ellos se contactan mucho con nosotros porque nosotros proponemos producir alimentos sanos y ellos recuperar territorio, entonces se compacta mucho. (Torres, entrevista personal, 2017)

Estos encuentros a los que se refiere el profesor son espacios conjuntos, que giran en torno a temas de interés común en lo cultural y lo educativo, tales como la reivindicación de saberes populares y ancestrales, las estrategias económicas autogestionarias y la soberanía alimentaria. Dichos procesos conjuntos han Ilevado a que ambas partes visiten las experiencias de los otros con una voluntad de aprender y construir desde la acción conjunta y el diálogo. 
En un primer momento, con el objetivo de conocerse y afirmar confianzas; luego, con la intención de avanzar en proyectos conjuntos para fortalecer a las comunidades con las cuales trabajan, que para muchos son las mismas porque varios profesores afiliados a Asoinca, no solo laboran en instituciones de resguardo que son lideradas por indígenas, sino son profesores indígenas y líderes del CRIC que están afiliados a Asoinca y apoyan las acciones de defensa de la educación y del territorio propuestas por el sindicato o por el CRIC.

Precisamente, el proyecto de soberanía alimentaria que se implementa a lo largo del departamento es un ejemplo de diálogo de saberes entre las dos organizaciones. Este proceso se convirtió en un elemento de convergencia tanto para el trabajo conjunto y la acción de resistencia como para la configuración del diálogo desde el escenario epistémico. Allí las organizaciones confluyen en el concepto y discurso sobre la soberanía alimentaria, un profesor indígena y un profesor del colectivo de Asoinca comentan:

Nosotros hablábamos era de alimentación propia y ahora de soberanía alimentaria. También logramos entender que, ser soberano es poder tener las semillas de nosotros no depender de otros, entonces por ahí nos fuimos entendiendo como en la cuestión con Asoinca. Entonces encontramos que nos retroalimentaron a nosotros, y nosotros también a ellos. (Bermúdez, entrevista, 2017)

Hay que manejar dos conceptos: seguridad alimentaria es una cosa y soberanía es otra. Seguridad es tener toda la alimentación, todos los productos vengan de donde vengan para poder abastecer a las familias; la soberanía es tener los productos con una producción propia de las familias, es producir nuestras propias hortalizas, nuestras propias verduras y manejar nuestros propios recursos. Es manejar los conocimientos propios, reconocer y recorrer la misma región. (F. Rivera, entrevista, 2017)

La soberanía alimentaria se entiende como una premisa básica de la autodeterminación de los pueblos con la intención de producir un alimento sano y saludable para consumirlo en familia y fortalecer el proceso comunitario sin tener que depender de lo que llega. No es un asunto solamente de producir o una cuestión de definición académica, como lo afirman profesores, sino un asunto político, una posibilidad para vivir y confrontar la producción capitalista, los problemas de nutrición, la industria agroquímica, el cultivo de transgénicos, el consumismo y la pobreza que se vive.

Desde estas apuestas, las dos organizaciones se encuentran y se fortalecen en sus acciones en educación popular y educación propia. Los profesores indígenas afiliados a Asoinca o al CRIC, que lideran procesos de soberanía alimentaria, reconocen los aportes mutuos y las perspectivas 
políticas y educativas convergentes. Estos aportes se expresan con mayor intensidad en las experiencias de soberanía alimentaria, en las que confluyen trayectos y proyectos de ambos procesos organizativos. A continuación presentamos el diálogo de un profesor indígena:

Nosotros ya veníamos trabajando acá con el proceso de recuperar la alimentación propia, entonces encontramos que lo que ellos venían proponiendo y lo que nosotros veníamos haciendo, nos apoyábamos. Entonces hicimos parte de ese proceso. Hoy nosotros también aportamos mucho a la parte del programa de soberanía alimentaria en Asoinca y ellos también, pues nos orientan y acompañan. (Bermúdez, entrevista, 2017)

En Asoinca se venían desarrollando desde el 2005 las huertas, las parcelas, los proyectos de alimentación sana o los procesos de recuperación de semillas en las instituciones educativas (El Caucano, 2005). En el caso del CRIC, la propuesta tiene antecedentes en su preocupación por recuperar la alimentación propia, pero estos dos trayectos se encuentran en el diálogo sobre el escenario educativo.

La intención de llevar la soberanía alimentaria a la escuela se concreta en ambas organizaciones, bajo el ideal de "producir, alimentarse y ejercer la resistencia y soberanía alimentaria" (El Caucano, 2009, p. 15) formando a los estudiantes, padres y profesores en la producción de alimentación sana y saludable para la familia y la comunidad, al tiempo que se aprenden los conocimientos escolares desde propuestas como las huertas, la cría de animales, la tienda escolar, el restaurante, entre otros.

Las experiencias pedagógicas sustentadas en la soberanía alimentaria buscan "orientar su proyecto de vida a partir de la reflexión sobre sus hábitos y costumbres, crear conciencia de su realidad, para generar cambio de actitudes frente a sí mismos y hacia los demás" (Asoinca, 2014, p. 21); esta es una manera de recuperar prácticas de consumo saludables, propias, acompañadas de la defensa del territorio. Lo más interesante es constatar cómo esta confluencia de búsquedas y sentidos posibilita diálogos y diseños curriculares que afirman los sentidos emancipadores de las prácticas educativas de las dos organizaciones.

Ahora bien, este diálogo en torno a sus prácticas políticas y pedagógicas también lo encontramos en las reflexiones que elaboran los protagonistas, al buscar, más que diferencias, confluencias en estas dos tradiciones latinoamericanas: la educación popular y la educación propia. Se reconoce una complementariedad de sentidos pedagógicos emancipadores y prácticas transformadoras, en varios niveles.

Como ya se señaló, coinciden en su cuestionamiento y distanciamiento con la educación hegemónica; tanto los dirigentes magisteriales como los educadores de base insisten en la crítica al modelo educativo 
capitalista y colonial, que impulsan las políticas educativas gubernamentales. Asimismo, coinciden en el sentido emancipatorio de su acción educativa; sus discursos están atravesados por sentidos alter-nativos como la defensa del territorio, de la tierra, de la salud y el cuidado del otro que se asocia a las nuevas sensibilidades de las teorías críticas, coherentes con la educación popular y propia.

Aunque la educación propia y la popular tienen sus trayectorias y proyectos, estas asumen y reconocen una perspectiva política para la educación, una más cercana al fortalecimiento y emancipación de la cultura ancestral, y la otra a la formación de sujetos populares para la transformación y construcción realidades. También, desde la educación propia y la educación popular se pretende fortalecer las relaciones entre las organizaciones y las escuelas con la intención de reivindicar sus derechos; defender la autonomía y la soberanía educativa con base en el derecho de las comunidades a decidir sobre su vida y fortalecer la democracia directa y asamblearia en la toma de decisiones en la escuela.

En este sentido, podríamos decir con Emil Palechor que más que diferencias o distinciones, el diálogo de saberes ha posibilitado relaciones y convergencias entre estas tradiciones educativas.

La relación entre educación popular y educación propia, relación no distinción. Creo que sí se tratase de una distinción estaríamos hablando de dos condiciones políticas distintas, la Educación popular y la educación propia tienen una apuesta política popular, que las identifica y las une. [...]. Porque la educación propia se está dando acogida de visibilizar y resignificar los pueblos ancestrales indígenas, y también existen pueblos ancestrales afrodescendientes: ¿Entonces estaríamos hablando de otra clase de educación?, no, estamos hablando es de la apuesta política desde lo educativo y lo pedagógico respecto a una educación popular o a una Educación Propia. (Palechor, entrevista, 2017)

Las propuestas educativas que se basan en una u otra tienen objetivo en común. Así también lo expresan Fernando Farinango: "la educación propia y la educación popular, aunque por diferentes caminos, vamos al mismo objetivo", y Alirio Alegría: "la coincidencia no es una coincidencia, sino que hablar de educación propia y hablar de educación popular, yo diría que lo único que cambia es el rótulo, el título, yo he tenido muy claro que nos identificamos inmediatamente" (entrevista, 2017).

Queda el desafío de continuar en la reflexión en torno a esta confluencia entre las dos corrientes educativas emancipadoras. Ello implica no solo profundizar en sus fundamentos, sino también sistematizar prácticas educativas concretas donde confluyan ambas tradiciones. Este camino ya se ha iniciado en el contexto de la reciente colaboración entre Asoinca, el CRIC y la Universidad Pedagógica Nacional. 


\section{Referencias}

Asoinca. (2005). Huertas escolares. Ejemplo de resistencia en las escuelas y colegios. El Caucano, 20, 7-8.

Asoinca. (2009). Soberanía y resistencia alimentaria. El Caucano, 28, 15-16.

Asoinca. (2014). Hacia una educación popular [Editorial]. Pensamiento Popular, 1, 9-10.

Bolaños, G. y Tatay, L. (2012). La educación propia: una realidad de resistencia educativa cultural de los pueblos. Educación y ciudad, 22, 45-56.

Brandão, C. R. (2006). O que é educação popular. Editora Brasilense.

Consejo Regional Indígena del Cauca, CRIC. (2009). Caminando la palabra de los congresos del CRIC. Febrero de 1974 a marzo de 2000. Gobierno VasCO-CRIC.

Freire, P. (1970). Pedagogía del oprimido. Siglo xxı.

Freire, P. (2006). Pedagogía de la tolerancia. Organización y notas de Ana María Araújo Freire. Fondo de Cultura Económica.

González, M. I. (2005). La escuela: espacio de reconocimiento de la interculturalidad. Pedagogía y Saberes, 22, 75-88.

González M. I. (2011). Movimiento Indígena y educación intercultural. México: Clacso-unam.

González, M. I. (2015). Educación en movimientos indígenas: historias, conflictos y propuestas. Universidad Nacional Autónoma de México, Programa de Estudios Latinoamericanos.

Guiso, A. (2015). Del diálogo de saberes a la negociación cultural. Recuperar, deconstruir, resignificar y recrear saberes. Pensamiento Popular, 2, 28-37.

Santos, B. de S. (2000). Renovar la teoría crítica y reinventar la emancipación social: encuentros en Buenos Aires. Clacso.

Torres, A. (1993). La educación popular y lo pedagógico. Evolución reciente y actuales búsquedas. La Piragua, 17, 24-31.

Torres, A. (2007). Identidad y política de la acción colectiva. Universidad Pedagógica Nacional.

Torres, A. (2008). La educación popular: trayectoria y actualidad. El Búho.

Torres, A. (2012). El potencial emancipador de la educación popular como práctica política y pedagógica. La Piragua, 37, 6-15.

Torres, A. (2016). Educación popular y movimientos sociales en América Latina. Biblos.

Walsh, C. (2009). Interculturalidad, Estado y sociedad. Luchas (de)coloniales de nuestra época. Abya Yala. 